\title{
Measurement of pulmonary arterial pulse wave reflection from single-slice phase-contrast and steady-state free precession MRI
}

\author{
Peter Leimbigler ${ }^{1 *}$, Joshua van Amerom ${ }^{1,2}$, Lars Grosse-Wortmann ${ }^{2,3}$, Shi-Joon Yoo ${ }^{2,3}$, Chris Macgowan ${ }^{1,2}$ \\ From 15th Annual SCMR Scientific Sessions \\ Orlando, FL, USA. 2-5 February 2012
}

\section{Summary}

Pulmonary arterial hypertension (PAH) is associated with elevated pulmonary vascular resistance, resulting in increased reflection of pressure and flow waves from distal vessels ${ }^{1}$. The gold standard for assessing PAH is right heart catheterization, an invasive procedure that carries a $5 \%$ risk of major complications ${ }^{2}$. We validate a noninvasive method for quantifying pulmonary arterial reflection using phase-contrast (PC) and steady-state free precession (SSFP) sequences acquired in a single slice.

\section{Background}

An arterial segment approximates a hydraulic transmission line terminated distally by a reflection site that partially reflects forward-traveling pressure and flow $(q)$ waves back toward the heart ${ }^{3}$. Due to finite pulse wave velocity $(P W V)$, backward-traveling waves are minimal in early systole (Figure 1); since arterial cross-sectional area $(a)$ increases roughly linearly with pressure, $P W V=$ $\partial q(t) / \partial a(t)$. Combining this with the water hammer equation yields an expression for the backward flow wave $^{4}$ :

$<$ center $>q_{\mathrm{b}}(t)=\left[q_{\text {meas }}(t)-P W V \times a(t)\right] / 2,</$ center $>$ from which arterial reflection magnitude $(R)$ can be computed in the frequency domain:

$<$ center $>R(\omega)=Q_{\mathrm{b}}(\omega) / Q_{\mathrm{f}}(\omega) .</$ center $>$

\section{Methods}

The right pulmonary artery in three healthy adult volunteers was imaged on a 1.5 T MR system (Siemens, Germany) using retrospectively ECG-gated cine PC and

'Medical Biophysics \& Medical Imaging, University of Toronto \& Hospital for Sick Children, Toronto, ON, Canada

Full list of author information is available at the end of the article
SSFP sequences to quantify blood velocity and vessel cross-section, respectively. PC and SSFP images were co-registered in MATLAB (The MathWorks, USA). The arterial lumen was outlined semi-automatically using Segment (Medviso, Sweden), yielding flow and area time series that were resolved into forward and backward flow waves in MATLAB. The frequency-domain ratios of backward to forward flow waves yielded estimates of $R$ which were then averaged over the fundamental heart frequency and the next two harmonics ${ }^{3}$ and compared to literature values using a two-tailed Student's $t$-test.

\section{Results}

The single-slice MRI method reliably resolved forward and backward flows in vivo (Figure 2), enabling noninvasive measurement of normal right pulmonary arterial reflection magnitudes, $R(\mathrm{SD})=0.34(0.05)$, statistically equivalent $(p=0.74)$ to invasively measured literature values $^{5}$ of $R(\mathrm{SD})=0.33(0.13)$.

\section{Conclusions}

The feasibility of single-slice MRI measurement of pulmonary arterial reflection in healthy adults motivates follow-up studies in adult and pediatric patient populations and lays the groundwork for noninvasive assessment of pulmonary hypertension.

\section{Funding}

This study was supported by the Canadian Institutes of Health Research (App \#199854).

\section{Author details}

${ }^{1}$ Medical Biophysics \& Medical Imaging, University of Toronto \& Hospital for Sick Children, Toronto, ON, Canada. ${ }^{2}$ Diagnostic Imaging, Hospital for Sick 


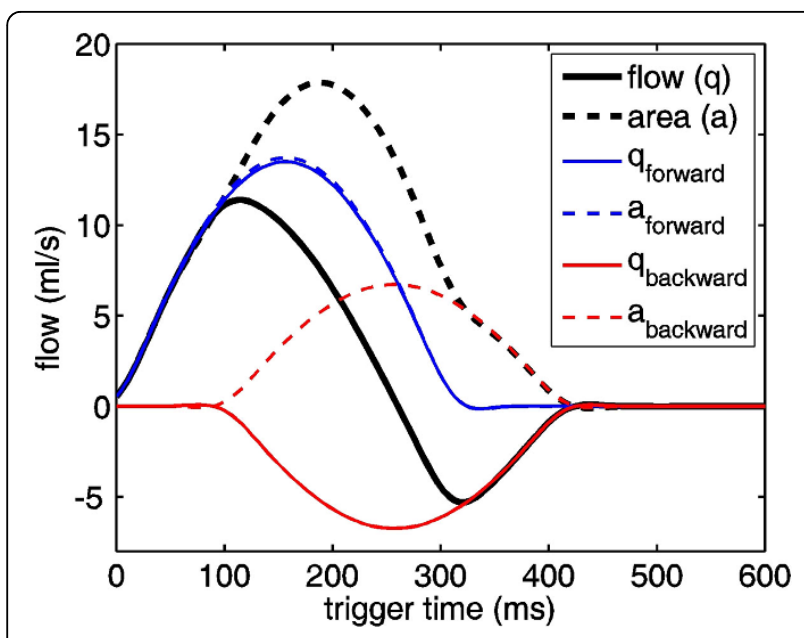

Figure 1 Illustration of single-slice wave separation. Before the onset of backward waves, flow and area are related by the constant factor PWV. Backward-traveling flow and area waves are equal in form but opposite in sign, and are proportional to the difference between $P W V \times$ area and flow.

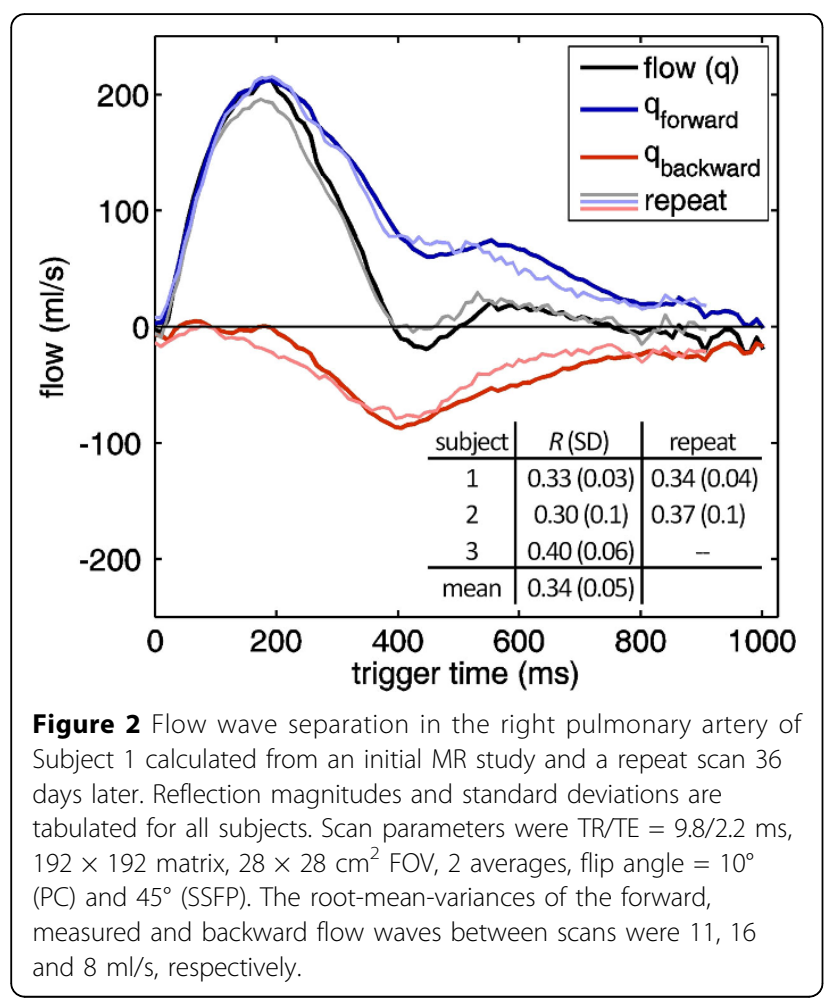

Children, Toronto, ON, Canada. ${ }^{3}$ Labatt Family Heart Centre, Toronto, ON, Canada.

Published: 1 February 2012

\section{References}

1. Weinberg, et al: Circulation. 2004, 110(17):2609-17.

2. Carmosino, et al: Anesth Analg. 2007, 104(3):521-7.

3. Milnor : Hemodynamics., 21989.
4. Parker : Med Biol Eng Comp. 2009, 47(2):175-88.

5. Laskey, et al: J Am Coll Cardiol. 1993, 21(2):406-12.

doi:10.1186/1532-429X-14-S1-W35

Cite this article as: Leimbigler et al:: Measurement of pulmonary arterial pulse wave reflection from single-slice phase-contrast and steady-state free precession MRI. Journal of Cardiovascular Magnetic Resonance 201214 (Suppl 1):W35.

\section{Submit your next manuscript to BioMed Central} and take full advantage of:

- Convenient online submission

- Thorough peer review

- No space constraints or color figure charges

- Immediate publication on acceptance

- Inclusion in PubMed, CAS, Scopus and Google Scholar

- Research which is freely available for redistribution 